\title{
A Framework of Next Generation Adaptive CNC Controller
}

\author{
Muhammad Azri Othman, Mohamad Minhat, Zamberi Jamaludin
}

\begin{abstract}
Modern manufacturing industries have increasingly demanded to bring comprehensive input data described using high-level languages such as STEP-NC, rather than outdated G\&M codes into computer numerical control machine tool levels. In current dynamic shop floor environments, predefined numerical control (NC) command generated in early stages is regularly found unusable or unsuitable for the dedicated resources, causing useless efforts used up in the initial process planning and NC code generation. This research aims to propose a new structure of an adaptive CNC controller by taking the advantages of well-known IEC61499 and STEP-NC standards. For realising adaptive CNC controller capability, integration of the native process planning decision-making function into CNC controller will be established. The activities such as cutting tool selection, machining parameter determination and toolpath generation will be issued automatically by the controller itself that subject to available online machine resources. The generic STEP-NC file is employed as data input and arranged accordingly in the IEC 61499 function block software editor. The system is developed in the JAVA environment by using proposed language.
\end{abstract} Function Block; CNC

\section{INTRODUCTION}

The advanced of computing technology has heralded a significant change in computer numerical control (CNC) machine tool development. CNC machine tools have come a long way. From a simple machine with a controller that lacked memory and a punched tape-driven mechanism, numerical control (NC) machine tools ultimately transformed into advanced machine tool systems embedded with high-technology features. Such features include multiple axis control, multiple process manufacturing, error compensation and adaptive control ([2]; [4]). The architecture of current CNC system is illustrated in Fig.1. By offering high performance with the highly automated operational ability, today $\mathrm{CNC}$ have undertaken more processing tasks especially for complicated machining tasks and large production scale. From design to machining operation, various types of decision-making tasks and numerous manufacturing resources are involving at each respective levels and domains of manufacturing activities

Revised Manuscript Received on September 10, 2019.

Muhammad Azri Othman, Faculty of Manufacturing Engineering, Universiti Teknikal Malaysia Melaka, Hang Tuah Jaya, 76100 Durian Tunggal, Melaka, Malaysia, Center for Diploma Studies, Universiti Tun Hussein Onn Malaysia, Parit Raja, 86400 Batu Pahat, Johor, Malaysia (Email: mazri@uthm.edu.my)

Mohamad Minhat, Faculty of Manufacturing Engineering, Universiti Teknikal Malaysia Melaka, Hang Tuah Jaya, 76100 Durian Tunggal, Melaka, Malaysia

Zamberi Jamaludin, Faculty of Manufacturing Engineering, Universiti Teknikal Malaysia Melaka, Hang Tuah Jaya, 76100 Durian Tunggal, Melaka, Malaysia
Keywords: Adaptive Controller; STEP-NC; IEC61499

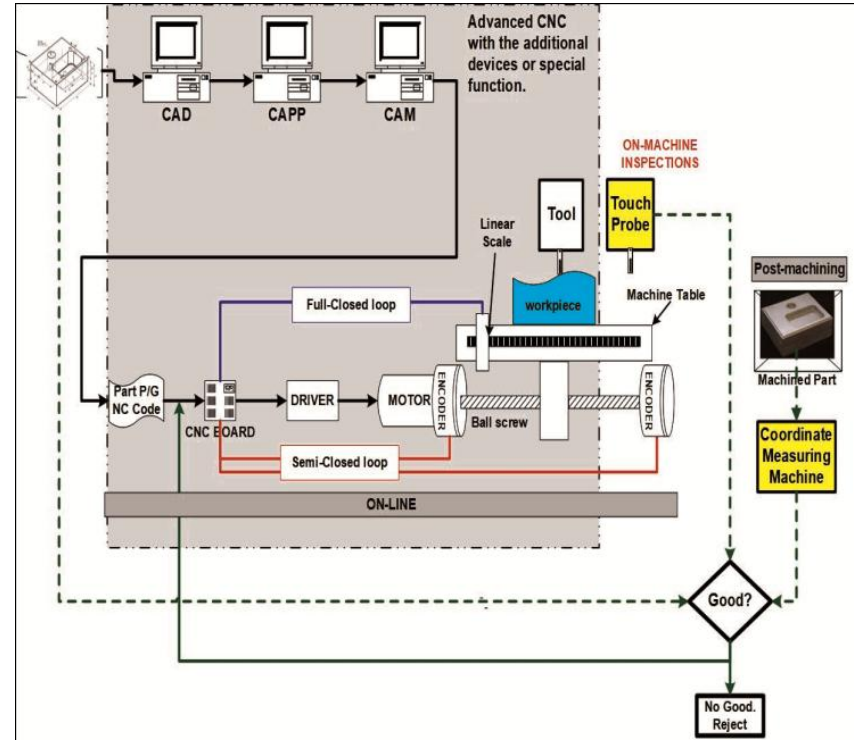

Fig. 1: Current advanced CNC system [5]

Along with this growth in development of next generation CNC systems, however, there is increasing concern over existing CNC systems that still continue utilise outdated and low-level codes as a programming language. This language is limited to small information and remain inflexible of the closed nature architecture of machine tools [12]. These limitations become major issues that need to be resolved for powerful and intelligent $\mathrm{CNC}$ system in future.

Due to complex and dynamic shop floor environments nowadays, the flexibility of the existing CNC systems to react adaptively and dynamically are believed to be limited because the way they are being programmed remains unchanged. Reflect to that situation, predefined NC commands generated in early stages regularly found unusable or unsuitable for the dedicated resources, causing useless efforts used up in advanced process planning tasks and NC program generation activity. Additionally, with lack of intelligence and usage of low-level information in process planning, make detailed machining process mostly are depends on $\mathrm{CAM}$ programmers rather than $\mathrm{CNC}$ machine tool data feedback. This reliance on planners is due to the incapability of controller systems to interpret feedback forms of data [14]. Consequently, productivity is dropped since machines remain idle to wait re-adjust process planning activities and re-generate the command code being acting.

The incapability of current $\mathrm{CNC}$ systems to cater stringent customer demands and quality requirements in total are the core reason behind growing demand and efforts

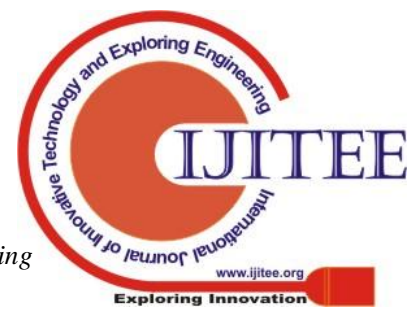


for synergize the CNC machine tool system capability to become more adaptive, interoperable and open [9]. Implementing STEP-NC will allow for high-level and standardised information to be sustained until machine-level stage. With the availability of high-level information embedded in the new breed of CNC controllers, a new possibility for adaptive control strategies can be realised. In such strategies, final NC code generation and execution are conducted in the controller modules themselves.

The purpose of this research is to develop a new structure of adaptive $\mathrm{CNC}$ controllers by merging function block and STEP-NC standard. In the proposed structure, the controller itself is embedded with the native decision-making as well as process control abilities. The idea is to increase the adaptiveness and dynamical of CNC controller system by generation of machine specific data at the machine tool level itself on the basis of available online machine resources rather than at early stages of process planning. The framework for the proposed adaptive controller is then outlined and discussed.

\section{OVERVIEW OF ISO14649 (STEP-NC) AND IEC 61499 (FUNCTION BLOCK)}

The development of the ISO 14649 standard, also known as STEP-NC, started in 2002 through an international intelligent manufacturing project involving Korea, the European Union, USA and Switzerland ([8]; [13]). STEP$\mathrm{NC}$ is an extended version of the Standard for the Exchange of Product model data, commonly known as STEP, for a machine tool. This standard aims to overcome pole holes or the lacking effectiveness in existing STEP application protocols (AP) involving data exchange with CNC. Once development is complete, STEP-NC is believed to provide a faultless, structured and standardised data model for $\mathrm{CNC}$ machine tool systems. Basically, STEP-NC is not a programming method such as G-code that describes cutting tool locations for specific CNC machines. By contrast, STEP-NC delivers an object-oriented data model which uses a feature-based method. This feature describes 'what' is to be made, and then only the machine controller will decide 'how' the code should be executed to make the product [8]. The information providers in STEP-NC includes not only geometry and topology information but also machining process information such as cutting tools description, operation attributes and workplan.

As a neutral data exchange standard independent of any device or machine, STEP-NC enables bidirectional data flow between CAx-process chains. As a result, seamless integration between CAx chains is facilitated. This integration is advantageous as data leakage or redundancy from multiple entering information is eliminated. Exchanging the existing CNC language with STEP-NC is not about merely changing the CNC programming language; such exchange also significantly affects next generation $\mathrm{CNC}$ controllers and whole manufacturing systems in total [4]. Employment of STEP-NC establishes the method of bringing comprehensive and high-level information into the machine level. With the availability of important information (e.g. part features, material type, machining method and resource availability, i.e. machine and tool description), the optimisation of machining parameters can automatically be conducted in the shop floor. The modification can then be fed back upstream. Thus, a bidirectional data flow environment is realised.

On the other hand, IEC 61499 extends the notion of programmable Function Blocks (FBs) from the IEC 61131-3 standard on the basis of an explicit event-driven model. With internal algorithm encapsulate inside, the FBs can be designed to function like a circuit or an electronic device [6]. Moreover, this FBs can then represent a small task in a control plan or can be encapsulated with multiple control units. Hence, FB can offer more portable form than what an existing automated control system have now. Technically, an individual FB in the network is only executed when it triggered by the event that it received. If not, FB will remain or returns to the idle state. From the design perspective, IEC 61499 provides the system-level view and the increased portability of event-driven components. With event-driven invocation offers by $\mathrm{FB}$, the system reaction time was improved. In addition, the use of FBs makes the control device openly programmable and easily reconfigurable [6]. Three standard classes of FBs are defined in IEC 61499: basic FBs, composite FBs and service interface FBs.

Many researchers have reported their studies on $\mathrm{CNC}$ machining by STEP-NC and FB standards. Areas involved includes process planning ([3]; [10]), controller ([1]; [6], sustainability [7] and optimisation [9]. STEP-NC and IEC $61499 \mathrm{FB}$ as two methods for interoperable milling have been discussed in depth by [13] In the present study, advantages and disadvantages of the two approaches with regard to different aspects of interoperability were documented and summarised (Table 1).

The combination of these two standards complete the data model provided by STEP-NC merged with the IEC 61499 FB feature and provide intelligent functionality to the next generation of CNC systems. IEC 61499-compliant devices can easily interface one another, thus providing seamless distribution of different tasks across various devices. Employing FBs in developing CNC controller will providing systems with extra autonomy and intelligence to improve handling and adapting to changes. Such improvement will result in further successful fulfilment of manufacturing objectives. 
Table 1. Technology enabled for Interoperable Machining [13]

\begin{tabular}{|c|c|c|}
\hline Area of interest & STEP-NC & IEC 61499 FBs \\
\hline $\begin{array}{lr}\text { Support } & \text { bi- } \\
\text { directional } & \text { flow } \\
\text { among CAx } & \text { system }\end{array}$ & $\begin{array}{l}\text {-Extended version of STEP standard for NC } \\
\text { application. Thus, changes done at the machine } \\
\text { level enable to saved and transfer back to the } \\
\text { upsteam. }\end{array}$ & $\begin{array}{l}\text {-Provides a limited support for establishing } \\
\text { bi-directional data flow between CAx chain } \\
\text { and CNC } \\
\text { - Its more appropriate to the logic control and } \\
\text { communication at device level }\end{array}$ \\
\hline 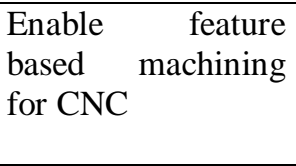 & $\begin{array}{l}\text { - Through feature-based machining concepts via } \\
\text { hierarchy of workingstep, STEP-NC provides } \\
\text { related task information to a CNC machine tool. }\end{array}$ & $\begin{array}{l}\text {-Able to merge FBs together with machining } \\
\text { features. } \\
\text { - Has possibility to be uses as new NC } \\
\text { language }\end{array}$ \\
\hline $\begin{array}{lr}\text { Establish } & \text { an } \\
\text { intelligent } & \text { CNC } \\
\text { system } & \end{array}$ & $\begin{array}{l}\text {-By providing comprehensive information to shop } \\
\text { floor, machine tools can have intelligent ability } \\
\text { and can perform several high-level tasks } \\
\text { autonomously and intelligently. }\end{array}$ & $\begin{array}{l}\text { - Through development of specific } \\
\text { algorithms inside the FBs, intelligent system } \\
\text { can be established }\end{array}$ \\
\hline $\begin{array}{ll}\text { Provide } & \text { CNCs a } \\
\text { fault- } & \text { tolerance } \\
\text { feature } & \end{array}$ & $\begin{array}{l}\text { - No specific function. However, STEP-NC can } \\
\text { assist the controller to be fault-tolerable by } \\
\text { provides necessary information to a controller }\end{array}$ & $\begin{array}{l}\text { - Since FBs are resource driven, it capable to } \\
\text { make decision at runtime and adapt } \\
\text { themselves to new environment. } \\
\text { - If anything happen at current machine, FBs } \\
\text { can be rearrange to another machine for } \\
\text { continue the rest of machining process as } \\
\text { fault recovery }\end{array}$ \\
\hline $\begin{array}{lr}\text { Internet } & \text { data } \\
\text { sharing } & \text { and } \\
\text { distributed } & \text { scenario }\end{array}$ & $\begin{array}{l}\text { - Via Extensible Markup Language (XML), that } \\
\text { also identified as Part 28. Distributed and } \\
\text { collaborative manufacturing scenario can be } \\
\text { achieved. }\end{array}$ & $\begin{array}{l}\text { - When the embedded algorithms inside FB } \\
\text { is being triggered, machining status can be } \\
\text { monitoring. Meanwhile, for remoting } \\
\text { machine in a distributed environment, FBs } \\
\text { can be transmitted using network. }\end{array}$ \\
\hline $\begin{array}{l}\text { Offer reusability, } \\
\text { modularity and } \\
\text { openness features } \\
\text { to CNC }\end{array}$ & $\begin{array}{l}\text { - Provides high-level information with vendor } \\
\text { independent characteristic, reusability and } \\
\text { openness CNC realised via STEP-NC } \\
\text {-In term of machining data interoperability issue, } \\
\text { STEP-NC is taking advantage of the current ISO } \\
10303 \text { modularity features }\end{array}$ & $\begin{array}{l}\text { - FBs able to be recycle to create another } \\
\text { process plans for another job task. } \\
\text {-Programmer can adjust the modular design } \\
\text { of a basic FB or reconnect a subset of basic } \\
\text { FBs to build a composite FB. }\end{array}$ \\
\hline $\begin{array}{l}\text { Be tailorable, } \\
\text { scalable, } \quad \text { and } \\
\text { extensible }\end{array}$ & $\begin{array}{l}\text { - Established with Tailor-ability, scalability, and } \\
\text { extensibility in mind like other STEP APs. } \\
\text { Through conformance class (CCs), the } \\
\text { implementer can progress, or scale up, to a more } \\
\text { complex CCs once the initial CCs have been } \\
\text { implemented. }\end{array}$ & $\begin{array}{l}\text { - As a machine independent architecture } \\
\text { design tool, FBs internal algorithms able to } \\
\text { be extended or tailored to fit a new system } \\
\text { condition. }\end{array}$ \\
\hline $\begin{array}{l}\text { Increase the } \mathrm{CNCs} \\
\text { portability to deal } \\
\text { with several } \\
\text { manufacturing } \\
\text { resource }\end{array}$ & $\begin{array}{l}\text { - It is possible to remain STEP-NC file in generic } \\
\text { data. Without any native data, it can be executed } \\
\text { on several machine tool controllers }\end{array}$ & $\begin{array}{l}\text {-FBs are carried to CNC machine tool as a } \\
\text { generic language format. Thus, readdressed } \\
\text { to different machine for local optimization } \\
\text { and execution is allowed }\end{array}$ \\
\hline
\end{tabular}




\section{CHALLENGES IN DEVELOPING STEP-NC CNC SYSTEM}

One of the aims of next generation CNC systems is to develop more interoperable and intelligence $\mathrm{CNC}$ system that capable to provide quick response to any dramatically market demand changes and the need of customised products ([4]; [12]). Various strides must be taken for product design data to reach $\mathrm{NC}$ data in machining, including setup planning, process sequencing, process selection, machine and tool selection, toolpath planning, parameter optimisation and NC program generation. Thus, to develop the next generation of $\mathrm{CNC}$ systems, several challenges need to be taken into consideration in designing and implementing the architecture of the system. The challenges can be summarised as follows.

(1) Responsiveness and adaptivity of the STEP-NC controller must be realised through the IEC 61499 FBlayered structure. For that purpose, generic STEP-NC data is used as input for the controller system. The data will retain their generic nature until a controller system populates the process plan with native manufacturing information to generate a native NC program. The machine native program can be adjusted at shop-floor level accordingly.

(2) Online or local optimisation of a NC program through native process planning at machine-level should be accomplished. The controller of a machine is well known for its capabilities, dynamics and run-time status. Thus, an optimal process plan can be readily achieved through the design of application-dependent algorithms and can be easily fed back upstream.

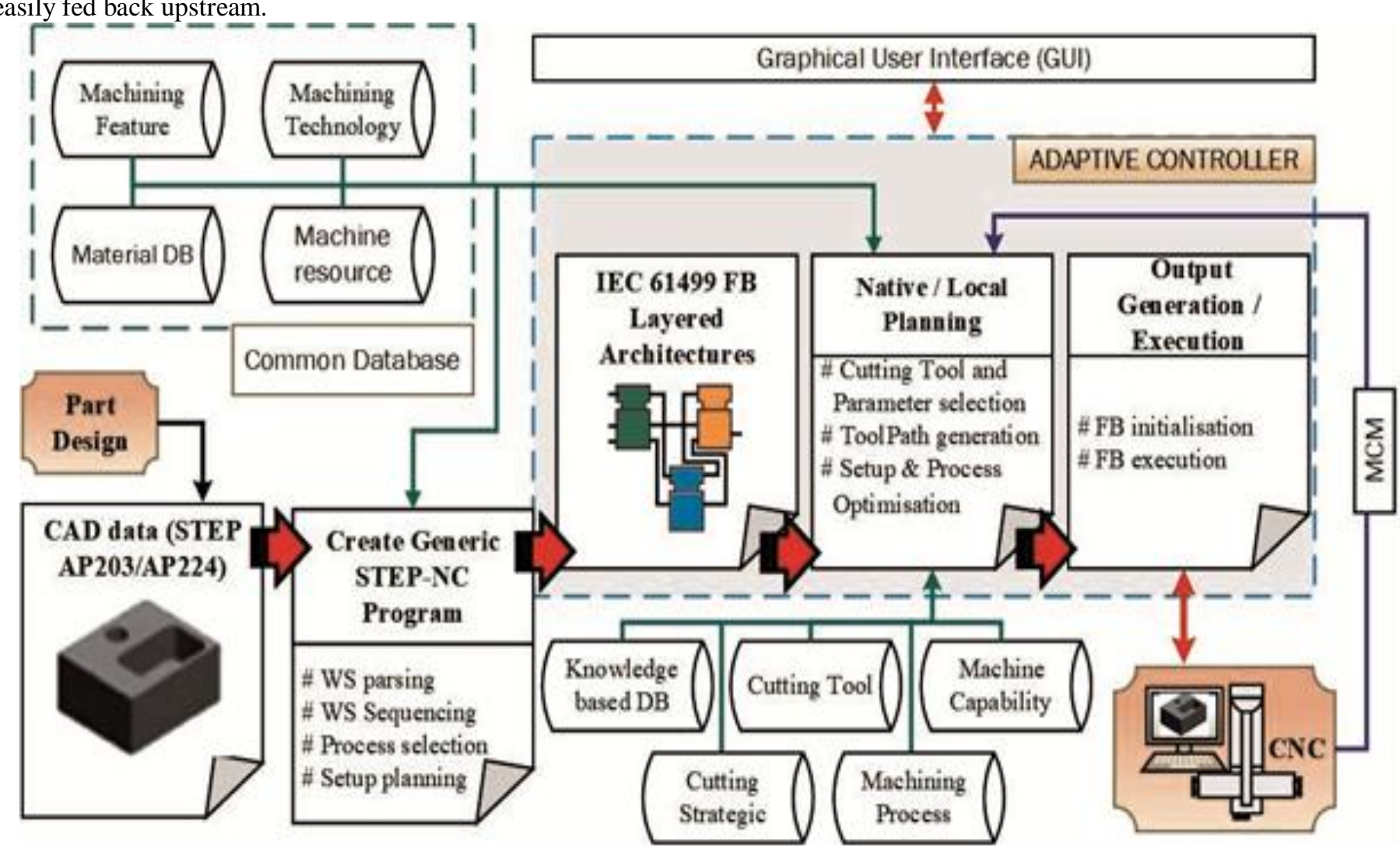

Fig. 2: Proposed Adaptive machining systems
(3) Openness, portability and interchangeability of the CNC machine tool should be enhanced by using FBs as internal controller language. With an embedded generic process plan, a FB can be directed freely according to shop floor configurations and CAD/CAM-independent systems.

\section{FRAMEWORK OF AN ADAPTIVE CONTROLLER BASED ON STEP-NC/FUNCTION BLOCK \& RESULTS}

To enhancing the level of autonomous CNC controller system, the proposed system is using generic STEP-NC as data model interface (Fig. 2). By doing that, CNC controller is being provides by high level information to support their intelligent function. Since STEP-NC itself does not embed any intelligent functionality because it is a passive data model. The IEC 61499 is used as controller internal language for processing and for execution control within the software-based control system. In other word, IEC 61499 $\mathrm{FB}$ is used to provide intelligent function for the propose system. In the end of this research project, a new structure of software-based CNC controller called Adaptive STEP$\mathrm{NC} / \mathrm{FB}$ controller will be developed. The controller has capability to automatically generate machine specific information and native process planning such as selected reasonable cutting tool, determination of best machining parameter and online toolpath generation, reflected based on available online resources. This controller is supported with GUI interface to provide an easy, efficient and user-friendly system. 


\subsection{Data preparation stage}

In the data preparation stage, input data is arranged for the proposed adaptive controller system. The primary function of this stage is to prepare a generic STEP-NC part program for the proposed system. Basically, the first task is part design. This task can be conducted by using commercial Unigraphics software, such as NX, Solidworks or CATIA. Then, part design is saved or exported as a STEP AP 203/AP 242 file to be used later in creating the generic STEP-NC program. To extract data from the STEP AP 203 file, JAVA Standard Data Access Interface (JSDAI) is used. In this study, a JAVA-programmed system is developed using ECLIPSE IDE to identify different manufacturing features from the product model, with JSDAI as interface to the JAVA program. At this stage, working steps parsing, working steps sequencing, process selection and setup planning activities are conducted. The output of this stage is generic STEP-NC data file in part 21 format.

\subsection{Online process planning and adaptive process control} stage

This stage obtains generic information and provides detailed updates in the form of a part program based on available online manufacturing resources to generate native or local planning data for the specific machine tool. The stage starts with generic STEP-NC being converted and arranged accordingly to the IEC 61499 FB structure. Once the machine resource is connected to the controller system, the online process planning module triggers and runs analyses based on performance criteria and machinability to automatically assign the reasonable cutting tool and issues the best machining parameters. Following with the generation a machining toolpath data in the end of the process. The toolpath generated by this controller is directly be used to drive the open architecture machine tool for machining without any intermediate file. The advantages of this structure, including the execution of the same STEP-NC file on different machine structures that will be able to provide different optimal spindle speeds, feed rates and toolpaths. This structure allows the controller to have an enhanced-capability mechanism, where decision-making and control strategies are attained within the controller level.

A graphic user interface will be developed as part of the system module which provides $3 \mathrm{D}$ visualisation display and acts as input and output manager of the entire system. Modification of the program at shop-floor level can be performed using the input console provided by the module. Besides providing machining toolpath and 3D model display, the system also visualises others related machining information, such as part feature information, fixture and jig information, setup information, stock information, machine resource information and cutting tool information.

\section{CONCLUSION}

Dealing with fluctuations and uncertainties in a dynamical machining environment led to research for CNC machine tool systems that could establish real-time process control and online optimisation. By bringing comprehensive data model and high-level information into $\mathrm{CNC}$ machine level via STEP-NC will allows the CNC controller to have direct intelligent control mechanisms, like cutting tool selection, machining parameters and toolpaths generation. A new approach and framework of STEP-compliant CNC systems were presented in this study. By combining the STEP-NC data model with IEC 61499 FB, modular process plans can be assembled quickly and dispatched directly to controllers for integrated planning and control for improved productivity.

The proposed system also adopts a distributed process planning architecture concept, where generic and machinespecific information are categorised. The generic STEP-NC file is used as input file for the system. However, internal structure data required by the $\mathrm{CNC}$ machine controller for machining execution will only be generated by the controller itself after a machine is finally assigned. Such data can also be regenerated upon dynamic changes during the machining process. The idea is to send algorithms on low-level NC programs to CNC controllers instead to enable adaptive decision at runtime upon dynamic changes in the machine level. Currently, we are developing the softwarebased controller, Adaptive STEP-NC/FB. This controller can interpret generic STEP-NC program files and enable them to generate and optimise machining parameters on the basis of present machine resource information.

\section{ACKNOWLEDGEMENT}

The authors would like to appreciate Ministry of Higher Education, Universiti Tun Hussein Onn Malaysia (UTHM), and Universiti Teknikal Malaysia Melaka (UTeM) for the financial support and facilities provided.

\section{REFERENCES}

1. Elias, D. M., Y. Yusof, and M. Minhat, 2012. Design and Machining Control via Interoperable Function Blocks and STEP-NC Data Model. International Conference on Flexible Automation and Intelligent Manufacturing, 239_ 244.

2. Han, Z., P. Hu, D. Han, and H. Fu, 2012. A framework of STEP-NC manufacturing system integrating CAD CAPP, CAM and CNC. 16th International Conference on Fluid Dynamic and Mechanical and Electrical Control Engineering, FDMECE 2012, November 10, 2012 November 11, 2012, 233, 365-368.

3. Ji, W., L. Wang, A. Haghighi, M. Givehchi, and X. Liu, 2016. A reachability based approach for machining feature sequencing. Journal of Manufacturing Systems, 40, 96-104

4. Liu, R., C. Zhang, and S.T. Newman, 2006. A framework and data processing for interfacing CNC with AP238. International Journal of Computer Integrated Manufacturing, 19(6), 516-522.

5. Minhat, M. 2009. Development of a STEP-NC Controller. PhD Thesis, University of Auckland.

6. Minhat, M., V. Vyatkin, X. Xu, S. Wong, and Z. AlBayaa, 2009. A novel open CNC architecture based on STEP-NC data model and IEC 61499 function blocks. Robotics and Computer-Integrated Manufacturing, 25(3), 560-569.

7. Peng, T., X. Xu, and L. Wang, 2014. A novel energy demand modelling approach for $\mathrm{CNC}$ machining based on function blocks. Journal of Manufacturing Systems, 33(1), 196-208. 
8. Qiu, X. L., L. Ding, and Y. Xing, 2006. Feature-based Process Planning using STEP-NC. International Technology and Innovation Conference 2006, (70102010), 1790-1795.

9. Ridwan, F., and X. Xu, 2013. Advanced CNC system with in-process feed-rate optimisation. Robotics and Computer-Integrated Manufacturing, 29(3), 12-20.

10. Wang, L., 2015. An overview of function block enabled adaptive process planning for machining. Journal of Manufacturing Systems, 35, 10-25.

11. Wang, L., H.-Y. Feng and N. Cai, 2003. Architecture design for distributed process planning. Journal of Manufacturing Systems, 22(2), 99-115.

12. Xu, X. W., and S.T. Newman, 2006. Making CNC machine tools more open, interoperable and intelligenta review of the technologies. Computers in Industry, 57(2), 141-152.

13. Xu, X. W., Wang, L., and Y. Rong, 2006. STEP-NC and function blocks for interoperable manufacturing. IEEE Transactions on Automation Science and Engineering, 3(3), 297-308.

14. Zhang, X., A. Nassehi, M. Safaieh, and S.T. Newman, 2013. Process comprehension for shopfloor manufacturing knowledge reuse. International Journal of Production Research, 51(23/24), 7405-7419. 